\title{
Novos táxons em Apomecynini (Coleoptera, Cerambycidae, Lamiinae)
}

\author{
Ubirajara R. Martins ${ }^{1,3}$ \\ Maria Helena M. Galileo ${ }^{2,3}$
}

\begin{abstract}
New taxa of Apomecynini (Coleoptera, Cerambycidae, Lamiinae). The following new taxa are described from Brazil: Ischioncha rondonia sp. nov., from Rondônia; Prosenella unicolor sp. nov., from Rio Grande do Sul; Catuaba gen. nov., type species, C. sanguinolenta sp. nov., from Mato Grosso do Sul.
\end{abstract}

Keywords. Apomecynini; Cerambycidae; Coleoptera; Lamiinae; Neotropical.

\section{INTRODUÇÃO}

As espécies americanas da tribo Apomecynini foram revistas por BREUNING (1971) que considerou Adetini Lacordaire, 1872; Ischiolonchini Lacordaire, 1872; Ptericoptini Lacordaire, 1872 e Agenopsini Lacordaire, 1872, como sinônimas. LinsLEY \& CHEMSAK (1984) revalidaram Adetini "based on a comparison with the genus Apomecyna we consider Adetus to be sufficiently distinct to maintain the tribe Adetini for the neo-tropical fauna."

$\mathrm{Na}$ realidade, os táxons descritos aqui se enquadrariam em Ischiolonchini, mas a revalidação desta tribo necessita de estudos muito mais aprofundados.

As siglas citadas no texto correspondem ao Museu Nacional, Universidade Federal do Rio de Janeiro, Rio de Janeiro (MNRJ) e ao Museu de Zoologia, Universidade de São Paulo, São Paulo (MZSP).

\section{Ischioloncha rondonia sp. nov.}

(Fig. 1)

Colorido geral avermelhado com as bases dos antenômeros IV a XI recobertas por anel de pubescência esbranquiçada. Fronte mais longa do que larga com pontuação fina e moderadamente esparsa. Lobos oculares inferiores $(0,6 \mathrm{~mm})$ mais curtos do que as genas $(0,8 \mathrm{~mm})$. Lobos superiores dos olhos estreitos, mais distantes entre si do que o quádruplo da largura de um lobo. Tubérculos anteníferos bem separados, curtos e agudos para o ápice. Escapo gradualmente engrossado para a extremidade, aplanado no lado inferior; pouco mais curto (comprimento $1,7 \mathrm{~mm}$ ) do que o antenômero III $(2,1 \mathrm{~mm})$. Antenômero III engrossado, fusiforme, com pêlos curtos, esparsos em toda a superfície. Antenômero IV $(2,0 \mathrm{~mm})$ subigual em comprimento ao III. Antenômeros V a X com comprimento gradualmente decrescente. Antenômero XI apenas mais longo do que o precedente com o ápice curvo.

Protórax apenas mais longo do que largo; constrição basal mais acentuada do que a apical. Lados do protórax ao nível do terço posterior com pequeno tubérculo arredondado no topo. Pronoto recoberto por tênue pubescência esbranquiçada, um pouco mais adensada nos lados da metade basal; pontuação fina e esparsa.

Cada élitro com oito faixas ou manchas de pubescência amarelada densa: uma longitudinal, da base ao quarto anterior, entre o escutelo e o úmero; outra longitudinal, do quarto anterior até um pouco depois do meio, iniciada ao nível posterior e interna à primeira faixa e levemente alargada para a parte posterior; uma pequena mancha oblíqua, dorsal, situada ao nível do ápice externo da segunda faixa; faixa longitudinal, paralela e com o mesmo comprimento da primeira, subumeral; uma mancha pouco maior, mais anterior, externa à mancha precedente; quarto apical com outras três faixas e/ou manchas (uma faixa paralela à sutura, mais larga para o ápice, uma mancha dorsal, ao nível anterior dessa faixa e uma faixa lateral). Ápice dos élitros arredondados em conjunto.

Face ventral com uma faixa de pubescência esbranquiçada nos mesepimeros e uma faixa de pubescência dourada de cada lado do metasterno. Metatíbias levemente engrossadas para o ápice.

Dimensões, em mm, macho. Comprimento total, 10,3;

\footnotetext{
1. Museu de Zoologia, Universidade de São Paulo. Caixa Postal 42594, 04299-970 São Paulo-SP, Brasil.

2. Museu de Ciências Naturais, Fundação Zoobotânica do Rio Grande do Sul. Caixa Postal 1188; 90001-970 Porto Alegre-RS, Brasil.

3. Pesquisador CNPq.
} 

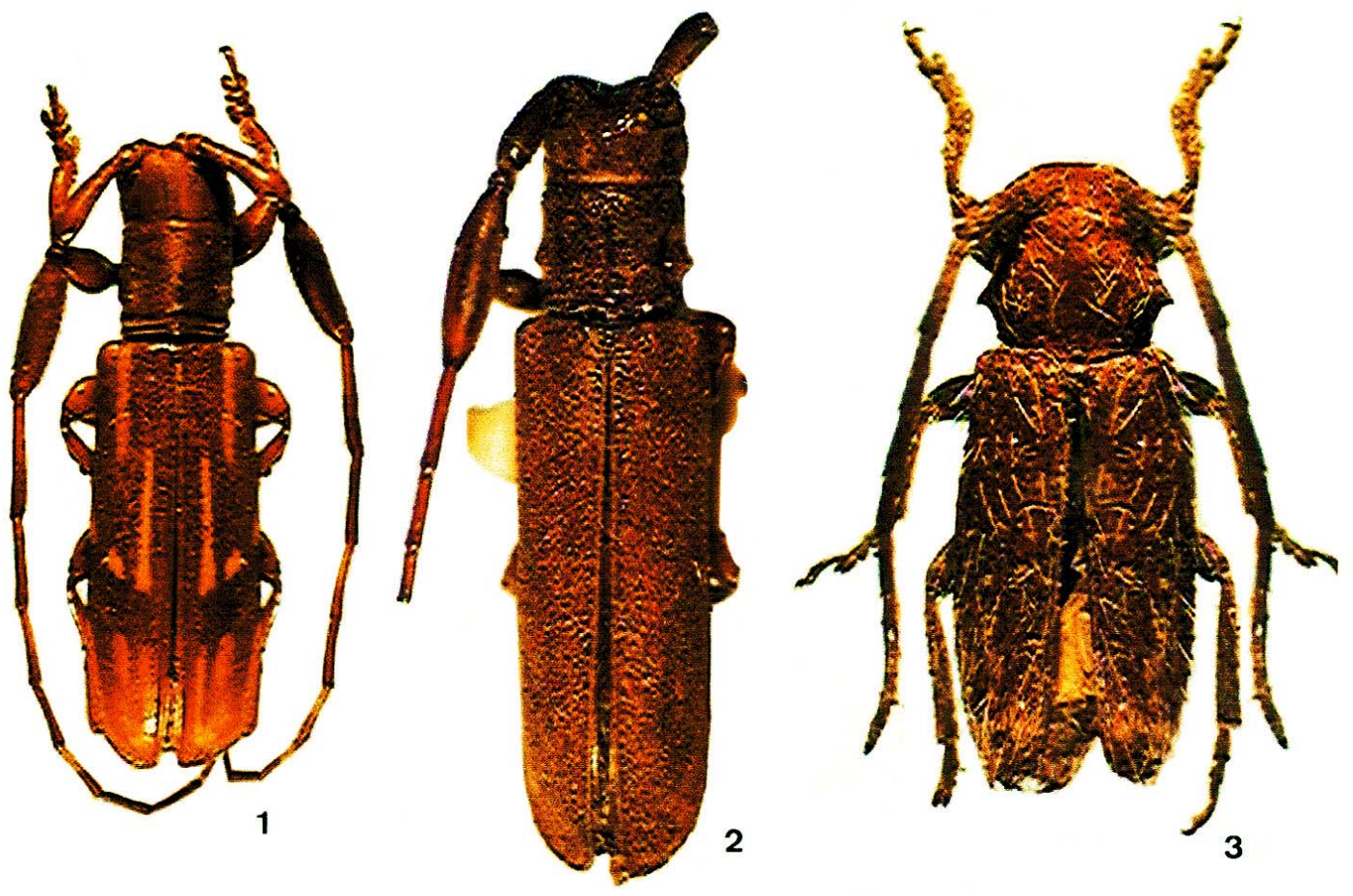

Figs. 1-3. 1, Inschioloncha rondonia sp. nov., holótipo macho; 2, Prosenella unicolor, sp. nov., holótipo macho; 3, Catuaba sanguinolenta sp. nov., holótipo macho.

comprimento do protórax ,1,9; maior largura do protórax, 2,0; comprimento do élitro, 7,1; largura umeral, 2,6.

Material-tipo. Holótipo macho procedente do Brasil, Rondônia, Ouro Preto, VIII.1980, B. Silva col. (MNRJ).

Discussão. Ischioloncha rondonia, pelos lobos inferiores dos olhos sensivelmente mais curtos do que as genas, assemelha-se a I. strandiella Breuning, 1942 e I. lineata Bates, 1885. Separa-se de ambas pela ausência de bandas longitudinais amarelas no pronoto. Além disso, difere de I. lineata, ocorrente na América Central, pelo padrão de colorido dos élitros onde as faixas longitudinais amareladas são interrompidas. Em $I$. lineata, as faixas são contínuas e vão da base ao ápice dos élitros. Separa-se de I. strandiella pelo tegumento corporal avermelhado e pelo padrão das faixas de pubescência dos élitros onde a faixa mais próxima da sutura está afastada da base e pelo antenômero III dos machos com pêlos curtos em toda superfície. Em I. strandiella (examinada através do diapositivo do holótipo), o tegumento corporal é preto, a faixa amarelada mais interna dos élitros quase atinge a base e o antenômero III não possui pêlos em toda superfície.

\section{Prosenela unicolor sp. nov.}

(Fig. 2)

Colorido geral vermelho-acastanhado. Todo o corpo revestido por pubescência branco-acinzentada, pouco densa.
Fronte subquadrada. Lobos oculares inferiores $(0,4 \mathrm{~mm})$ mais curtos do que as genas $(0,7 \mathrm{~mm})$. Lobos oculares superiores estreitos, mais distantes entre si do que o quintuplo da largura de um lobo. Escapo cilíndrico, com 1,0 mm de comprimento e mais curto do que o III. Antenômero III engrossado, fusiforme, sem pêlos e com pubescência esbranquiçada, comprimento $(1,8$ $\mathrm{mm})$ maior do que o IV $(1,0 \mathrm{~mm})$.

Protórax mais largo do que longo; constrições basal e apical com a mesma largura. Partes laterais com gibosidade discreta, ao nível do terço basal. Pronoto finamente pontuado.

Pontuação da base dos élitros densa; distância entre pontos menor que o diâmetro de um ponto. Friso sutural com pubescência esbranquiçada mais densa que o restante da superfície. Extremidades arredondadas em conjunto.

Dimensões, em mm, macho. Comprimento total, 7,6; comprimento do protórax, 1,2; maior largura do protórax, 1,5; comprimento dos élitros, 5,6; largura umeral, 1,8.

Material-tipo. Holótipo macho, proveniente do Brasil, Rio Grande do Sul, Caxias do Sul (Vila Oliva), 15.I.1963, P. Buck col. (MZSP).

Discussão. Prosenella unicolor assemelha- se a Prosella muehni Bruch, 1933, que ocorre na Argentina (Jujuy, Salta e Córdoba), mas difere pelo presença de tubérculo nos lados do protórax, pelos antenômeros basais avermelhados (antenas quebradas, a esquerda no meio do antenômero VI, e a direita, no ápice do escapo) e pela ausência de áreas glabras nos lados da base do pronoto. Em $P$. muehni, os lados do protórax são 
desarmados, os antenômeros basais são pretos e o pronoto tem uma área glabra de cada um dos lados da base.

\section{Catuaba gen. nov.}

Espécie tipo: Catuaba sanguinolenta sp. nov.

Etimologia. Tupi, katu $=$ muito; $a b a=$ pêlo. Alusivo à pilosidade abundante do corpo.

Todo corpo revestido por pêlos eretos, longos, brancos e pretos. Fronte convexa. Olhos não-divididos. Lobos oculares superiores estreitos, mais distantes do que o sêxtuplo da largura de um lobo. Lobos oculares inferiores mais longos do que as genas. Tubérculos anteníferos apenas projetados. Antenas com onze artículos. Nos machos, tão longas quanto o corpo. Escapo sem cicatriz apical, cilíndrico, tão longo quanto o antenômero III. Antenômero III não-engrossado, tão longo quanto o IV. Antenômeros V a XI com comprimentos gradualmente decrescentes.

Protórax mais largo do que longo com espinho lateral manifesto. Processo prosternal regularmente curvo. Mesosterno curto, no meio tão longo quanto o urosternito I. Processo mesosternal truncado para o lado do processo prosternal. Cavidades coxais intermediárias levemente abertas aos lados. Élitros com os lados paralelos; extremidades obliquamente truncadas e desarmadas. Fêmures clavados. Mesotíbias com entalhe na margem posterior depois do meio. Metatíbias nãoalargadas. Lados do último urosternito com pêlos pretos, longos e curvos.

Discussão. Catuaba gen. nov. reúne os caracteres utilizados na chave para gêneros (BREUNING 1971): protórax com espinho lateral bem desenvolvido; olhos bilobados; úmeros sem espinho; escapo desprovido de cicatriz apical e processo mesosternal truncado na borda anterior. Esse conjunto de caracteres conduz ao gênero Ptericoptus A.-Serville, 1835.
Catuaba difere consideravelmente de Ptericoptus pelas antenas não-engrossadas; pelos antenômeros basais desprovidos de franja densa no lado interno; pela pilosidade corporal e pelo mesosterno sem degrau na parte anterior.

\section{Catuaba sanguinoloenta sp. nov.}

(Fig. 3)

Tegumento preto, densamente revestido por pubescência vermelha e brilhante, entremeada por longas setas brancas na cabeça e no tórax. Essas setas brancas, nos élitros, estão entremeadas por setas pretas. Élitros com estreita faixa de pubescência branca anteapical e ápices com tegumento pretoavermelhado. Processo mesosternal com longos pêlos brancos. Pernas com o mesmo tipo de setas.

Dimensões, em mm. Comprimento total, 7,8; comprimento do protórax, 1,8; maior largura do protórax, 2,4; comprimento do élitro, 5,4; largura umeral 2,4.

Material-tipo. Holótipo macho procedente do Brasil, Mato Grosso do Sul: Vacaria, XII.1922, sem nome do coletor (MZSP).

Agradecimentos. Ao Dr. Renato C. Marinoni, Universidade Federal do Paraná, pelo empréstimo dos diapositivos dos tipos feitos pelo Pe J. S. Moure nos museus europeus e norte-americanos. A Jorge D. Soledar, Museu de Ciências Naturais, Fundação Zoobotânica do Rio Grande do Sul, pela execução das fotografias.

\section{REFERÊNCIAS}

Breuning, S. 1971. Revision des espèces américaines de la tribue des Apomecynini Lac. (Coleoptera, Cerambycidae). Entomologisches Abhandungen 37(3): 209-335.

Linsley, E. G. \& J. A. CHEMSAK. 1984. The Cerambycidae of North America. Part VII (1). Taxonomy and classification of the subfamily Lamiinae, tribes Parmenini through Acanthoderini. University of California Publications on Entomology 102: $\mathrm{X}+158$. 